\title{
Ventilator-Induced Diaphragmatic Dysfunction: Diagnosis and Role of Pharmacological Agents
}

\author{
Won-Young Kim MD MSc and Chae-Man Lim MD PhD
}

\author{
Introduction \\ Pathogenesis \\ Diagnosis \\ Ultrasonography \\ Treatment \\ Antioxidants \\ Theophylline \\ Summary
}

\begin{abstract}
The use of controlled mechanical ventilation results in a major reduction of diaphragmatic contractile force together with atrophy of diaphragm muscle fibers, which is a condition known as ventilatorinduced diaphragmatic dysfunction. Ventilator-induced diaphragmatic dysfunction is one of the major contributors to weaning difficulties and even increased mortality. This review summarizes the current data on the pathogenesis and diagnosis of ventilator-induced diaphragmatic dysfunction, and it outlines the use of ultrasonography for diaphragm evaluation. In addition, current pharmacologic agents used to mitigate ventilator-induced diaphragmatic dysfunction are described, with a particular emphasis on the therapeutic potential of theophylline in patients with ventilatorinduced diaphragmatic dysfunction-associated weaning difficulties. Key words: diaphragm; diaphragm dysfunction; mechanical ventilation; ultrasonography; theophylline; review. [Respir Care 2017;62(11):1485-1491. (C) 2017 Daedalus Enterprises]
\end{abstract}

\section{Introduction}

Controlled mechanical ventilation is associated with adverse effects on the structure and function of the diaphragm

\footnotetext{
Dr Kim is affiliated with the Department of Internal Medicine, Pusan National University School of Medicine, Busan, Republic of Korea. Dr Lim is affiliated with the Department of Pulmonary and Critical Care Medicine, Asan Medical Center, University of Ulsan College of Medicine, Seoul, Republic of Korea.

The authors have disclosed no conflicts of interest.

Correspondence: Chae-Man Lim MD PhD, Department of Pulmonary and Critical Care Medicine, Asan Medical Center, University of Ulsan College of Medicine, Seoul, Republic of Korea, 88 Olympic-ro 43-Gil, Songpa-gu, Seoul 05505, Republic of Korea. E-mail: cmlim@amc.seoul.kr
}

DOI: $10.4187 /$ respcare. 05622 in a condition known as ventilator-induced diaphragmatic dysfunction. ${ }^{1}$ The prevalence of diaphragmatic dysfunction has been reported to be up to 2-fold higher than the prevalence of ICU-acquired weakness ${ }^{2}$ and as high as $80 \%$ in patients with ICU-acquired weakness entering the weaning process. ${ }^{3}$ This phenomenon may be exacerbated by the use of neuromuscular blockers and steroids. ${ }^{4,5}$ In addition, recent studies have shown that the prevalence of diaphragmatic dysfunction already present at the time of ICU admission is as high as $64 \%$, suggesting that diaphragmatic dysfunction may constitute an under recognized form of organ failure in patients with critical illnesses such as sepsis. ${ }^{6,7}$ Ventilator-induced diaphragmatic dysfunction can increase weaning time and is associated with weaning outcome, ICU and hospital mortality, and long-term clinical outcomes. ${ }^{6,8-12}$ The duration of mechanical ventilation tended to be higher in patients with persistent dysfunction than in those with improving dysfunction. ${ }^{13}$ 
Moreover, maximal inspiratory pressure before extubation below $30 \mathrm{~cm} \mathrm{H}_{2} \mathrm{O}$ was found to be independently associated with increased risk of mortality at 1 year. ${ }^{12}$ This review outlines the current data on the pathogenesis and diagnosis of ventilator-induced diaphragmatic dysfunction, followed by a discussion on pharmacologic agents, in particular theophylline, that are currently used to mitigate ventilator-induced diaphragmatic dysfunction.

\section{Pathogenesis}

Controlled mechanical ventilation, even for a few hours, has been found to reduce diaphragmatic contractile force both in vitro and in vivo. ${ }^{14,15}$ Prolonged controlled mechanical ventilation in patients was found to trigger significant reductions in the generation of both active and passive diaphragm myofibrillar force by reducing myofibrillar protein levels. ${ }^{16}$ In addition to decreased diaphragmatic force, muscle fiber atrophy, resulting from reduction in protein synthesis and increased proteolysis by ubiquitin proteasomes, caspases, and calpains, has been reported in the diaphragms of animals with ventilator-induced diaphragmatic dysfunction. ${ }^{17-19} \mathrm{~A}$ landmark study reported marked atrophy of both slow- and fast-twitch fibers in the diaphragms of brain-dead organ donors who had undergone prolonged mechanical ventilation prior to organ harvest. ${ }^{20}$ These changes have been linked to an increased level of oxidative stress in the diaphragm. ${ }^{21}$ In addition, prolonged mechanical ventilation was found to trigger diaphragm autophagy via oxidative stress and the induction of Forkhead box O-1, thereby contributing to diaphragm muscle fiber atrophy. ${ }^{22}$ Lastly, other comorbidities and metabolic stresses, such as COPD, hyperglycemia, and sepsis, could negatively affect patients with ventilator-induced diaphragmatic dysfunction as well. $6,7,23$

\section{Diagnosis}

Accurate evaluation of diaphragmatic function in critically ill patients undergoing mechanical ventilation remains a difficult task. Although measuring maximal inspiratory pressure is relatively easy, this parameter is effort-dependent in that it represents the combined action of all inspiratory muscles, and it may be affected by underlying lung diseases. ${ }^{24,25}$ Transdiaphragmatic pressure can be measured by simultaneously recording esophageal and gastric pressures, but the interpretation of results depends on the level of patient cooperation. Phrenic nerve conduction is the accepted standard method of quantifying mechanical function of the diaphragm. However, phrenic stimulation techniques are heavily dependent on patient effort, require expertise and specialized equipment, and are time consum-

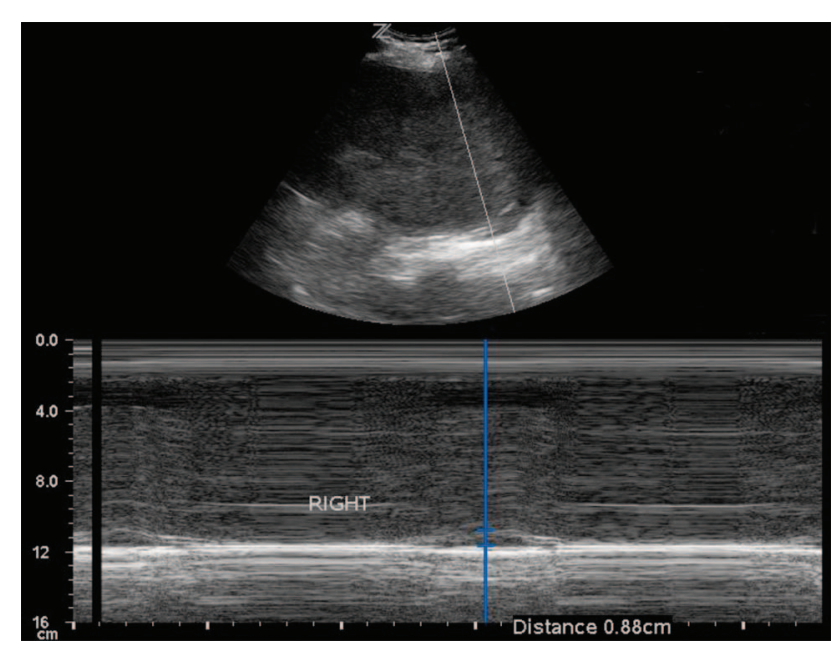

Fig. 1. B-mode was used to find the best approach and to select the exploration line of hemidiaphragm. During inspiration, diaphragmatic contraction was recorded by M-mode tracing, and the amplitude of excursion was measured on the vertical axis of the tracing from the baseline to the point of maximum height of inspiration on the graph.

ing, making them less than ideal for ICU patients. ${ }^{26}$ Diaphragmatic movement can be adequately assessed by fluoroscopy and magnetic resonance imaging 27,28 ; however, ionizing radiation, patient transportation, and high cost are limiting factors.

\section{Ultrasonography}

Ultrasonography is increasingly used in the ICU for diagnostic and therapeutic purposes. ${ }^{29}$ Ultrasonography does not involve patient transportation or exposure to ionizing radiation. Short examination time and high reproducibility of ultrasonography results are clear advantages in acute care settings. Diaphragmatic ultrasonography at bedside has been shown to be safe and easy to perform, while allowing both morphologic assessment (eg, detection of atrophy) and functional evaluation of the muscle with high inter-observer agreement. ${ }^{30,31}$

Two ultrasonography parameters are mainly used to assess diaphragmatic function: diaphragmatic excursion ${ }^{32}$ and thickening fraction of the diaphragmatic muscle ${ }^{33}$ during inspiration. Diaphragmatic excursion can be easily measured with a 3-5-MHz probe in either B- or M-mode (Fig. 1). Mean inspiratory diaphragmatic excursion in healthy subjects during quiet spontaneous breathing was found to be $1.34 \pm 0.18 \mathrm{~cm},{ }^{30}$ with diaphragmatic excursion $>2.5 \mathrm{~cm}$ in cardiac surgery patients being proposed as a cutoff for excluding severe diaphragmatic dysfunction. ${ }^{32}$ However, diaphragmatic excursion depends on the amount of ventilator support and PEEP; accordingly, a recent study indicated that diaphragmatic excursion should not be used to 

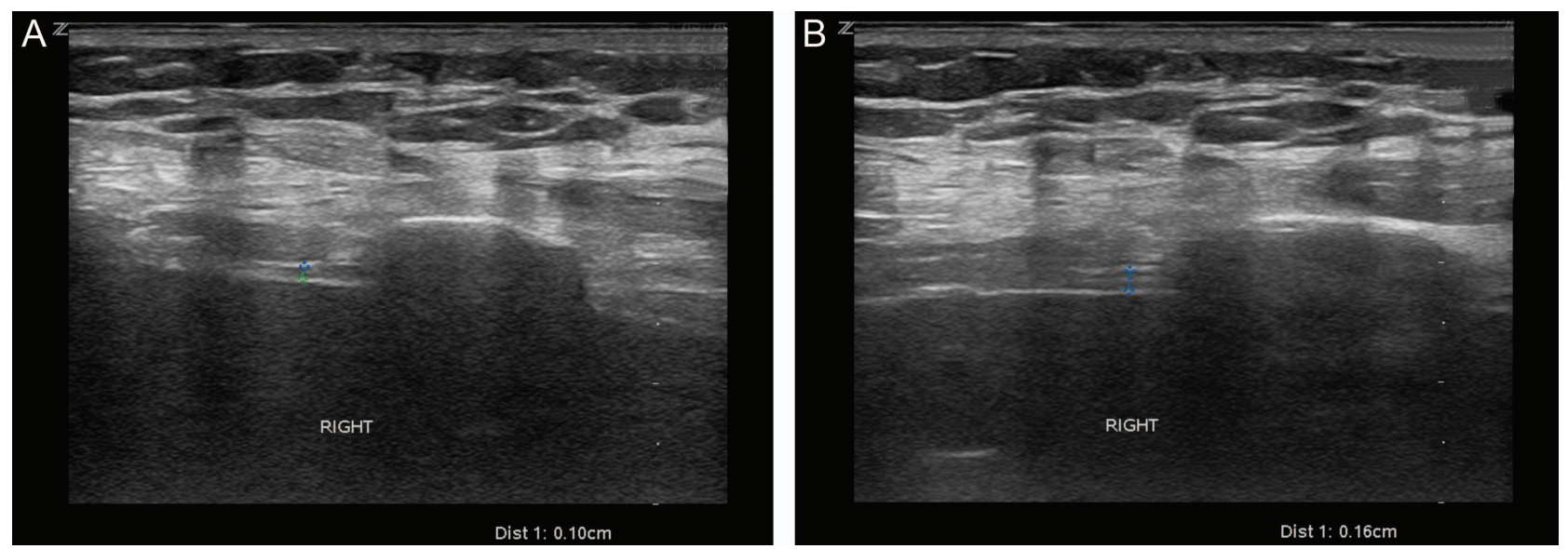

Fig. 2. B-mode view of diaphragm in the zone of apposition during expiration (A) and inspiration (B). The diaphragm is identified as a 3-layer structure (non-echogenic central layer bordered by two echogenic layers, the diaphragmatic pleurae and the peritoneum). Thickening fraction is defined as ([thickness at $B-$ thickness at $A]$ /thickness at $A$ ).

assess diaphragmatic contractility in patients receiving mechanical ventilation. ${ }^{34}$

The second parameter, thickening fraction of the diaphragmatic muscle, measures muscle thickening in the zone of apposition of the diaphragm to the rib cage with a probe $\geq 10 \mathrm{MHz}$ in B- or M-mode (Fig. 2). Thickening fraction is defined as [(thickness at end-inspiration - thickness at end-expiration)/thickness at end-expiration]. ${ }^{10,11}$ The mean normal thickness of the diaphragm at the zone of apposition in healthy, spontaneously breathing subjects while relaxing is $1.7 \pm 0.2 \mathrm{~mm}$, increasing to $4.5 \pm 0.9 \mathrm{~mm}$ when breath is held at total lung capacity. ${ }^{35}$ Diaphragm thickness may be regarded as a direct index of diaphragmatic contractility and may detect the presence of atrophy, although diaphragm thickness may also be influenced by lung volume. ${ }^{33,36}$ Both diaphragmatic excursion and thickening fraction have been shown to be correlated with functional measurements of diaphragmatic function in spontaneously breathing patients, ${ }^{32}$ and studies describing the use of ultrasonography evaluation of the diaphragm in the process of weaning suggest that either method can be a reliable predictor of weaning and extubation outcomes. ${ }^{8-11}$ For example, decreased diaphragmatic excursion $(<10 \mathrm{~mm})$ was found to be a predictor of weaning failure among subjects in medical ICUs, ${ }^{9}$ and a threshold of thickening fraction $>30-36 \%$ was associated with extubation success. ${ }^{10,11}$

\section{Treatment}

Several in vivo and clinical studies have demonstrated that maintaining spontaneous respiratory efforts during mechanical ventilation can alleviate ventilator-induced diaphragmatic dysfunction. ${ }^{37,38}$ The diaphragmatic atrophy rate in 40 intubated, critically ill adult subjects was re- cently evaluated by daily ultrasonography measurements of diaphragm thickness from the first day of mechanical ventilation until transfer to the general ward. Zambon et $\mathrm{al}^{38}$ found that the daily reductions in thickness were $7.5 \%$ during controlled mechanical ventilation, 5.3\% during high pressure support ventilation, and $1.5 \%$ during low pressure support ventilation. Interestingly, diaphragm thickness increased $2.3 \%$ under conditions of spontaneous breathing and CPAP. In another large cohort study, diaphragm thickness during mechanical ventilation over the first week of ventilation was assessed. ${ }^{39}$ In this study, diaphragm thickness decreased rapidly during the first several days of mechanical ventilation in $>40 \%$ of subjects, and this decreased was predicted by lower levels of inspiratory effort and higher levels of ventilatory support.

Mechanical ventilation has also been associated with increased oxidative stress in the diaphragm, even during pressure support ventilation or intermittent spontaneous breathing. ${ }^{40}$ Moreover, the effects of mechanical ventilation on diaphragmatic function may be exacerbated by medications such as steroids and neuromuscular blockers that are commonly used in treating these patients. ${ }^{4,5}$ These findings show that diaphragm weakening is inevitable to some extent and that there is a need for alternative therapeutic strategies for ventilator-induced diaphragmatic dysfunction, which might include antioxidants and inotropic agents (eg, theophylline, digoxin, and levosimendan) or phrenic nerve pacing. As for the latter, a recent study in animal models described a novel technology in which a single central-line catheter containing an array of integrated electrodes is used to perform bilateral phrenic nerve pacing in synchrony with the ventilator. ${ }^{41}$ The authors of this study reported that intermittent phrenic stimulation prevented the decline in diaphragm thickness and also 
tended to mitigate reductions in diaphragm muscle fiber. In this review, we focus on the use of antioxidants and theophylline for the prevention or treatment of ventilatorinduced diaphragmatic dysfunction.

\section{Antioxidants}

Prevention of mechanical ventilation-induced oxidative stress with the use of antioxidants can avoid diaphragmatic atrophy and contractile dysfunction that occur during prolonged mechanical ventilation. Aside from countering oxidative stress, antioxidants may also modulate the expression of proteolysis-related genes: eg, administration of high doses of vitamin $\mathrm{E}$ to animals reduced the expression of several proteases such as caspase- 3 and calpain. ${ }^{42}$ Trolox, an analog of vitamin $\mathrm{E}$ with antioxidant activity, was found to protect the diaphragm against ventilator-induced diaphragmatic atrophy. ${ }^{43,44}$ Mitochondria may be an important source of reactive oxygen species in the diaphragm during prolonged mechanical ventilation, with emission of mitochondrial reactive oxygen species playing a predominant role in mechanical ventilation-induced proteolysis, atrophy, and contractile dysfunction. ${ }^{45}$ Treatment of animals with SS-31, a mitochondria-targeting antioxidant, protected rat diaphragms against muscle atrophy that occurs during prolonged mechanical ventilation by countering oxidative stress and preventing protease activation. ${ }^{46}$ To date, however, no clinical studies have assessed the efficacy of antioxidants in patients with ventilator-induced diaphragmatic dysfunction.

\section{Theophylline}

Theophylline is widely prescribed as an add-on therapy for patients with poorly controlled asthma or COPD. Several molecular mechanisms of its action have been proposed: first, theophylline relaxes airway smooth muscles by inhibiting phosphodiesterase-3 activity, leading to bronchodilation. ${ }^{47}$ Second, therapeutic concentration of theophylline antagonizes adenosine $A_{1}$ and $A_{2}$ receptors, which also results in bronchodilation. ${ }^{48}$ Third, theophylline acts as an anti-inflammatory agent, increasing the effect of interleukin- $10^{49}$ and preventing the translocation of the pro-inflammatory transcription factor nuclear factor- $\kappa \mathrm{B} .{ }^{50}$ Theophylline also enhances histone deacetylase-2 activity, which is reduced by oxidative stress, and the increased histone deacetylase-2 activity reduces formation of peroxynitrite radicals. ${ }^{51,52}$ In addition to its bronchodilator and anti-inflammatory effects, theophylline stimulates the respiratory neuronal network ${ }^{53,54}$ and increases the activity of respiratory muscles, including the intercostal and transversus abdominis muscles, as well as the diaphragm. ${ }^{55-57}$
Taken together, these results suggest that theophylline may be therapeutic in patients with ventilator-induced diaphragmatic dysfunction-associated weaning difficulties. Theophylline was found to dose-dependently increase peak twitch tension in an in vitro model of isolated diaphragmatic fibers. ${ }^{58}$ A study using phrenic nerve conduction showed that theophylline infusion rapidly reversed the reduction of transdiaphragmatic pressure resulting from resistive loaded breathing in normal human subjects. ${ }^{59}$ Moreover, in subjects with severe COPD, theophylline significantly increased the maximal transdiaphragmatic pressure and suppressed diaphragmatic fatigue when compared with placebo. ${ }^{60}$ This phenomenon may be explained by previous findings showing that, under both fresh and fatigued conditions, theophylline is associated with greater improvements in diaphragmatic contractility at short than at long fiber lengths induced by acute hyperinflation. ${ }^{61}$ Conversely, a placebo-controlled, double-blind, crossover study investigating the effects of theophylline on recovery of respiratory motor function in subjects after spinal cord injury failed to detect improvements; the null results of this study was attributed to the high dropout rate of subjects due to adverse drug-induced systemic effects. ${ }^{54}$

Numerous studies have demonstrated favorable effects of theophylline on human respiratory muscle function, and the drug is commonly used in patients weaning from mechanical ventilation; however, with the exception of some case reports in patients with tetraplegia, few studies have systematically reported clinical experience with theophylline in adult patients weaning from mechanical ventilation. ${ }^{62,63}$ Recently, we demonstrated that low-dose (median, $200 \mathrm{mg} / \mathrm{d}$ ) theophylline treatment significantly improved the diaphragmatic movements in subjects who required mechanical ventilation for at least $72 \mathrm{~h}$, met the criteria for a spontaneous breathing trial, and had ultrasonography evidence of ventilator-induced diaphragmatic dysfunction. ${ }^{64}$ The effects of theophylline were much more prominent in diaphragms with ventilator-induced diaphragmatic dysfunction, consistent with previous studies reporting that the inotropic effect of theophylline was more prominent in fatigued diaphragms. ${ }^{59,60}$ In our study, theophylline was well tolerated by the study subjects, with no significant adverse drug reactions that prompted discontinuation. This may be due to a relatively low serum concentration (mean $=4.6 \mathrm{mg} / \mathrm{L}$ on day 3 ) of theophylline compared with studies that used higher doses of theophylline (mean serum concentration $\geq 10 \mathrm{mg} / \mathrm{L}$ ). Even low concentrations of theophylline $(<5 \mathrm{mg} / \mathrm{L})$ have been reported to restore histone deacetylase- 2 activity. ${ }^{51,52}$ The finding that lowdose theophylline significantly improved diaphragmatic movements is encouraging, considering that the drug is often withheld due to concerns about its adverse effects. ${ }^{54}$ However, we cannot conclude at this point that theophyl- 


\section{Ventilator-Induced Diaphragmatic Dysfunction}

line is useful for prevention or treating of patients with ventilator-induced diaphragmatic dysfunction. Our study had a small sample size and did not provide supporting molecular mechanisms. In addition, the multiple confounding factors (eg, comorbidity, severity of illness, cause of ICU admission, drugs) generally present in ICU patients may contribute to diaphragmatic dysfunction. Indeed, despite the similar baseline characteristics of the ventilatorinduced diaphragmatic dysfunction subjects in the theophylline and non-theophylline groups, most subjects were admitted to the ICU due to severe sepsis or septic shock ( $91 \%$ vs $84 \%$, respectively, $P=.65$ ), and many of them were treated with sedatives, neuromuscular blockers, and/or steroids.

\section{Summary}

Ventilator-induced diaphragmatic dysfunction is believed to be one of the major contributors to the weaning difficulties in ICU patients, and it significantly influences the duration of mechanical ventilation, weaning failure, and mortality. The increasing availability of ultrasonography has provided a simple and effective means of evaluating diaphragm function that may help in the design of adequate treatment. Mounting evidence shows that theophylline increases diaphragmatic contractility in a subset of patients with fatigued diaphragm and hyperinflated lungs; therefore, large prospective clinical trials using theophylline would help physicians choose the appropriate course of therapy for patients with ventilator-induced diaphragmatic dysfunction-associated weaning difficulties.

\section{REFERENCES}

1. Vassilakopoulos T, Petrof BJ. Ventilator-induced diaphragmatic dysfunction. Am J Respir Crit Care Med 2004;169(3):336-341.

2. Dres M, Dubé BP, Mayaux J, Delemazure J, Reuter D, Brochard L, et al. Coexistance and impact of limb muscle and diaphragm weakness at time of liberation from mechanical ventilation in medical intensive care unit patients. Am J Respir Crit Care Med 2017;195(1): 57-66.

3. Jung B, Moury PH, Mahul M, de Jong A, Galia F, Prades A, et al. Diaphragmatic dysfunction in patients with ICU-acquired weakness and its impact on extubation failure. Intensive Care Med 2016;42(5): 853-861.

4. Testelmans D, Maes K, Wouters P, Gosselin N, Deruisseau K, Powers $\mathrm{S}$, et al. Rocuronium exacerbates mechanical ventilation-induced diaphragm dysfunction in rats. Crit Care Med 2006;34(12):30183023.

5. Lieu FK, Powers SK, Herb RA, Criswell D, Martin D, Wood C, et al. Exercise and glucocorticoid-induced diaphragmatic myopathy. J Appl Physiol (1985) 1993;75(2):763-771.

6. Demoule A, Jung B, Prodanovic H, Molinari N, Chanques G, Coirault $\mathrm{C}$, et al. Diaphragm dysfunction on admission to the intensive care unit. Prevalence, risk factors, and prognostic impact: a prospective study. Am J Respir Crit Care Med 2013; 188(2):213-219.
7. Supinski GS, Callahan LA. Diaphragm weakness in mechanically ventilated critically ill patients. Crit Care 2013;17(3):R120.

8. Jiang JR, Tsai TH, Jerng JS, Yu CJ, Wu HD, Yang PC. Ultrasonographic evaluation of liver/spleen movements and extubation outcome. Chest 2004;126(1):179-185.

9. Kim WY, Suh HJ, Hong SB, Koh Y, Lim CM. Diaphragm dysfunction assessed by ultrasonography: influence on weaning from mechanical ventilation. Crit Care Med 2011;39(12):2627-2630.

10. DiNino E, Gartman EJ, Sethi JM, McCool FD. Diaphragm ultrasound as a predictor of successful extubation from mechanical ventilation. Thorax 2014;69(5):423-427.

11. Ferrari G, De Filippi G, Elia F, Panero F, Volpicelli G, Apra F. Diaphragm ultrasound as a new index of discontinuation from mechanical ventilation. Crit Ultrasound J 2014;6(1):8.

12. Medrinal C, Prieur G, Frenoy E, Robledo Quesada A, Poncet A, Bonnevie $\mathrm{T}$, et al. Respiratory weakness after mechanical ventilation is associated with one-year mortality: a prospective study. Crit Care 2016;20(1):231.

13. Demoule A, Molinari N, Jung B, Prodanovic H, Chanques G, Matecki S, et al. Patterns of diaphragm function in critically ill patients receiving prolonged mechanical ventilation: a prospective longitudinal study. Ann Intensive Care 2016;6(1):75.

14. Sassoon CS, Caiozzo VJ, Manka A, Sieck GC. Altered diaphragm contractile properties with controlled mechanical ventilation. J Appl Physiol (1985) 2002;92(6):2585-2595.

15. Capdevila X, Lopez S, Bernard N, Rabischong E, Ramonatxo M, Martinazzo G, et al. Effects of controlled mechanical ventilation on respiratory muscle contractile properties in rabbits. Intensive Care Med 2003;29(1):103-110.

16. Hussain SN, Cornachione AS, Guichon C, Al Khunaizi A, Leite Fde S, Petrof BJ, et al. Prolonged controlled mechanical ventilation in humans triggers myofibrillar contractile dysfunction and myofilament protein loss in the diaphragm. Thorax 2016;71(5): 436-445.

17. Shanely RA, Zergeroglu MA, Lennon SL, Sugiura T, Yimlamai T, Enns D, et al. Mechanical ventilation-induced diaphragmatic atrophy is associated with oxidative injury and increased proteolytic activity. Am J Respir Crit Care Med 2002;166(10):1369-1374.

18. DeRuisseau KC, Kavazis AN, Deering MA, Falk DJ, Van Gammeren D, Yimlamai T, et al. Mechanical ventilation induces alterations of the ubiquitin-proteasome pathway in the diaphragm. J Appl Physiol (1985) 2005;98(4):1314-1321.

19. McClung JM, Kavazis AN, DeRuisseau KC, Falk DJ, Deering MA, Lee $\mathrm{Y}$, et al. Caspase-3 regulation of diaphragm myonuclear domain during mechanical ventilation-induced atrophy. Am J Respir Crit Care Med 2007;175(2):150-159.

20. Levine S, Nguyen T, Taylor N, Friscia ME, Budak MT, Rothenberg $\mathrm{P}$, et al. Rapid disuse atrophy of diaphragm fibers in mechanically ventilated humans. N Engl J Med 2008;358(13):1327-1335.

21. Zergeroglu MA, McKenzie MJ, Shanely RA, Van Gammeren D, DeRuisseau KC, Powers SK. Mechanical ventilation-induced oxidative stress in the diaphragm. J Appl Physiol (1985) 2003;95(3):11161124.

22. Hussain SN, Mofarrahi M, Sigala I, Kim HC, Vassilakopoulos T, Maltais F, et al. Mechanical ventilation-induced diaphragm disuse in humans triggers autophagy. Am J Respir Crit Care Med 2010;182(11): 1377-1386.

23. Ottenheijm CA, Heunks LM, Dekhuijzen PN. Diaphragm muscle fiber dysfunction in chronic obstructive pulmonary disease: toward a pathophysiological concept. Am J Respir Crit Care Med 2007; 175(12):1233-1240.

24. Aldrich TK, Spiro P. Maximal inspiratory pressure: does reproducibility indicate full effort? Thorax 1995;50(1):40-43. 


\section{Ventilator-Induced Diaphragmatic Dysfunction}

25. Lisboa C, Pare PD, Pertuze J, Contreras G, Moreno R, Guillemi S, et al. Inspiratory muscle function in unilateral diaphragmatic paralysis. Am Rev Respir Dis 1986;134(3):488-492.

26. American Thoracic Society/European Respiratory S. ATS/ERS Statement on respiratory muscle testing. Am J Respir Crit Care Med 2002;166(4):518-624.

27. Chavhan GB, Babyn PS, Cohen RA, Langer JC. Multimodality imaging of the pediatric diaphragm: anatomy and pathologic conditions. Radiographics 2010;30(7):1797-1817.

28. Kiryu S, Loring SH, Mori Y, Rofsky NM, Hatabu H, Takahashi M. Quantitative analysis of the velocity and synchronicity of diaphragmatic motion: dynamic MRI in different postures. Magn Reson Imaging 2006;24(10):1325-1332.

29. Bouhemad B, Zhang M, Lu Q, Rouby JJ. Clinical review: Bedside lung ultrasound in critical care practice. Crit Care 2007;11(1): 205.

30. Boussuges A, Gole Y, Blanc P. Diaphragmatic motion studied by m-mode ultrasonography: methods, reproducibility, and normal values. Chest 2009;135(2):391-400.

31. Goligher EC, Laghi F, Detsky ME, Farias P, Murray A, Brace D, et al. Measuring diaphragm thickness with ultrasound in mechanically ventilated patients: feasibility, reproducibility and validity. Intensive Care Med 2015;41(4):642-649.

32. Lerolle N, Guerot E, Dimassi S, Zegdi R, Faisy C, Fagon JY, et al. Ultrasonographic diagnostic criterion for severe diaphragmatic dysfunction after cardiac surgery. Chest 2009;135(2):401-407.

33. Summerhill EM, El-Sameed YA, Glidden TJ, McCool FD. Monitoring recovery from diaphragm paralysis with ultrasound. Chest 2008;133(3):737-743

34. Umbrello M, Formenti P, Longhi D, Galimberti A, Piva I, Pezzi A, et al. Diaphragm ultrasound as indicator of respiratory effort in critically ill patients undergoing assisted mechanical ventilation: a pilot clinical study. Crit Care 2015;19:161.

35. Ueki J, De Bruin PF, Pride NB. In vivo assessment of diaphragm contraction by ultrasound in normal subjects. Thorax 1995;50(11): $1157-1161$

36. Cohn D, Benditt JO, Eveloff S, McCool FD. Diaphragm thickening during inspiration. J Appl Physiol (1985) 1997;83(1):291-296.

37. Gayan-Ramirez G, Testelmans D, Maes K, Racz GZ, Cadot P, Zador $\mathrm{E}$, et al. Intermittent spontaneous breathing protects the rat diaphragm from mechanical ventilation effects. Crit Care Med 2005;33(12): 2804-2809.

38. Zambon M, Beccaria P, Matsuno J, Gemma M, Frati E, Colombo S, et al. Mechanical ventilation and diaphragmatic atrophy in critically ill patients: an ultrasound study. Crit Care Med 2016;44(7):13471352.

39. Goligher EC, Fan E, Herridge MS, Murray A, Vorona S, Brace D, et al. Evolution of diaphragm thickness during mechanical ventilation: impact of inspiratory effort. Am J Respir Crit Care Med 2015;192(9): 1080-1088.

40. Futier E, Constantin JM, Combaret L, Mosoni L, Roszyk L, Sapin $\mathrm{V}$, et al. Pressure support ventilation attenuates ventilator-induced protein modifications in the diaphragm. Crit Care 2008;12(5): R116.

41. Reynolds SC, Meyyappan R, Thakkar V, Tran BD, Nolette MA, Sadarangani G, et al. Mitigation of ventilator-induced diaphragm atrophy by transvenous phrenic nerve stimulation. Am J Respir Crit Care Med 2017;195(3):339-348.

42. Servais S, Letexier D, Favier R, Duchamp C, Desplanches D. Prevention of unloading-induced atrophy by vitamin $\mathrm{E}$ supplementation: links between oxidative stress and soleus muscle proteolysis? Free Radic Biol Med 2007;42(5):627-635.

43. Betters JL, Criswell DS, Shanely RA, Van Gammeren D, Falk D, Deruisseau KC, et al. Trolox attenuates mechanical ventilation-in- duced diaphragmatic dysfunction and proteolysis. Am J Respir Crit Care Med 2004;170(11):1179-1184.

44. McClung JM, Kavazis AN, Whidden MA, DeRuisseau KC, Falk DJ, Criswell DS, et al. Antioxidant administration attenuates mechanical ventilation-induced rat diaphragm muscle atrophy independent of protein kinase B (PKB Akt) signalling. J Physiol 2007;585(Pt 1): 203-215.

45. Kavazis AN, Talbert EE, Smuder AJ, Hudson MB, Nelson WB, Powers SK. Mechanical ventilation induces diaphragmatic mitochondrial dysfunction and increased oxidant production. Free Radic Biol Med 2009;46(6):842-850.

46. Powers SK, Hudson MB, Nelson WB, Talbert EE, Min K, Szeto HH, et al. Mitochondria-targeted antioxidants protect against mechanical ventilation-induced diaphragm weakness. Crit Care Med 2011;39(7): 1749-1759.

47. Rabe KF, Magnussen H, Dent G. Theophylline and selective PDE inhibitors as bronchodilators and smooth muscle relaxants. Eur Respir J 1995;8(4):637-642.

48. Polosa R, Blackburn MR. Adenosine receptors as targets for therapeutic intervention in asthma and chronic obstructive pulmonary disease. Trends Pharmacol Sci 2009;30(10):528-535.

49. Mascali JJ, Cvietusa P, Negri J, Borish L. Anti-inflammatory effects of theophylline: modulation of cytokine production. Ann Allergy Asthma Immunol 1996;77(1):34-38.

50. Ichiyama $\mathrm{T}$, Hasegawa $\mathrm{S}$, Matsubara $\mathrm{T}$, Hayashi $\mathrm{T}$, Furukawa $\mathrm{S}$. Theophylline inhibits NF-kappa B activation and I kappa B alpha degradation in human pulmonary epithelial cells. Naunyn Schmiedebergs Arch Pharmacol 2001;364(6):558-561.

51. Cosio BG, Tsaprouni L, Ito K, Jazrawi E, Adcock IM, Barnes PJ. Theophylline restores histone deacetylase activity and steroid responses in COPD macrophages. J Exp Med 2004;200(5):689-695.

52. Hirano T, Yamagata T, Gohda M, Yamagata Y, Ichikawa T, Yanagisawa $\mathrm{S}$, et al. Inhibition of reactive nitrogen species production in COPD airways: comparison of inhaled corticosteroid and oral theophylline. Thorax 2006;61(9):761-766.

53. Nantwi KD, El-Bohy A, Goshgarian HG. Actions of systemic theophylline on hemidiaphragmatic recovery in rats following cervical spinal cord hemisection. Exp Neurol 1996;140(1):53-59.

54. Tzelepis GE, Bascom AT, Safwan Badr M, Goshgarian HG. Effects of theophylline on pulmonary function in patients with traumatic tetraplegia. J Spinal Cord Med 2006;29(3):227-233.

55. Nishii Y, Okada Y, Yokoba M, Katagiri M, Yanaihara T, Masuda N, et al. Aminophylline increases parasternal intercostal muscle activity during hypoxia in humans. Respir Physiol Neurobiol 2008;161(1): 69-75.

56. Yokoba M, Ichikawa T, Takakura A, Ishii N, Kurosaki Y, Yamada $\mathrm{Y}$, et al. Aminophylline increases respiratory muscle activity during hypercapnia in humans. Pulm Pharmacol Ther 2015;30:96101

57. Jagers JV, Hawes HG, Easton PA. Aminophylline increases ventilation and diaphragm contractility in awake canines. Respir Physiol Neurobiol 2009;167(3):273-280.

58. Viires N, Aubier M, Murciano D, Marty C, Pariente R. Effects of theophylline on isolated diaphragmatic fibers. A model for pharmacologic studies on diaphragmatic contractility. Am Rev Respir Dis 1986;133(6):1060-1064.

59. Aubier M, De Troyer A, Sampson M, Macklem PT, Roussos C. Aminophylline improves diaphragmatic contractility. N Engl J Med 1981;305(5):249-252.

60. Murciano D, Aubier M, Lecocguic Y, Pariente R. Effects of theophylline on diaphragmatic strength and fatigue in patients with chronic obstructive pulmonary disease. N Engl J Med 1984;311(6): 349-353. 


\section{Ventilator-INduced Diaphragmatic Dysfunction}

61. Gauthier AP, Yan S, Sliwinski P, Macklem PT. Effects of fatigue, fiber length, and aminophylline on human diaphragm contractility. Am J Respir Crit Care Med 1995;152(1):204-210.

62. Ferguson GT, Khanchandani N, Lattin CD, Goshgarian HG. Clinical effects of theophylline on inspiratory muscle drive in tetraplegia. Neurorehabilitation and Neural Repair 1999;13(3):191-197.
63. Bascom AT, Lattin CD, Aboussouan LS, Goshgarian HG. Effect of acute aminophylline administration on diaphragm function in high cervical tetraplegia: a case report. Chest 2005;127(2):658-661.

64. Kim WY, Park SH, Kim WY, Huh JW, Hong SB, Koh Y, et al. Effect of theophylline on ventilator-induced diaphragmatic dysfunction. J Crit Care 2016;33:145-150. 